Canadà̀

\title{
Rapid review
}

\section{Research initiatives with Southern partners on the impacts of Covid-19}

Laura Bolton

Institute of Development Studies

5 November 2021

\section{Question}

Identify rapid response research initiatives that are responding to the economic and social impacts of Covid-19. Identify any reported impact and lessons learned on approach.

\section{Contents}

1. Summary

2. Research programmes

3. Knowledge exchange initiatives

4. Organisation response

5. Funding network 


\section{Summary}

This review aimed to identify rapid research response mechanisms which were both in collaboration with Southern partners and focused on understanding socio-economic impacts of Covid-19. Projects that were identified fulfilled some but not all of these criteria.

It was not possible in many cases to identify the nature of involvement of Southern researchers in partnerships based on published information within the scope of this report. Evidence of increased autonomy, leadership, or decentralised decision making among organisations in the Global South was not detailed. Reflections on the strengths, weaknesses and challenges in the running of programmes and platforms included in this report were not identified. Many programmes are in their infancy and are not yet reflecting on process learning.

Research programmes and platforms identified:

- Partnership for Research on Progress and Resilience in Education (Centre for Global Development)

- BRAC Rapid Research Response

- African Population and Health Research Center Rapid Response Service

- Covid Collective (IDS)

- Covid-19 in the Global South (Southern Voice)

- Evidence Synthesis Response to Covid-19 Crisis (3ie)

- Health Policies and Systems (Health Systems Research Unit of the South African Medical Research Council)

- The Global South AI4COVID Program

- Periscope (Firoz Lalji Institute for Africa, London School of Economics)

- Covid-19 Learning, Evidence and Research Programme (CLEAR) (IDS)

- Scottish Research Council Global Challenges Research Fund (Rapid Response \& Covid-19) FY 202O-21 (University of St. Andrews funded by the Scottish Research Council)

- Partnership for Economic Policy (PEP) Rapid Response Initiative

- Maintains Programme: Research Supporting Social Services' Adaptation to External Shocks (Oxford Policy Management)

\section{Search strategy}

Keyword searches were carried out combining a number of search terms. Different combinations were used in different orders as no one search string was effectively discriminatory in terms of the research question. Search terms included: rapid research, initiative, covid 19, global south, researchers, donor, social, economic, development, policy.

Key organisations and think tanks such as the World Bank were reviewed. It is not possible to draw conclusions that organisations or think tanks do not have rapid research initiatives responding to the economic and social impacts of Covid-19. This would require a systematic review of larger scope than this rapid review. 


\title{
2. Research programmes
}

\author{
Partnership for Research on Progress and Resilience in Education \\ Centre for Global Development (CGD) \\ https://www.cgdev.org/project/partnership-research-progress-and-resilience-education
}

A research consortium run by CGD is in the early stages of studying the education challenges created by Covid-19. CGD are partnering with research organisations in Ghana, Senegal, Malawi, Kenya, and Pakistan. The partners include: the Institute for Educational Planning and Administration (IEPA), the University of Cape Coast, Ghana; the African Population and Health Research Center (APHRC) in Kenya; Centre for Educational Research and Training (CERT), and the Centre de Recherche pour le Développement Économique et Social (CRDES), Senegal. Partners are identifying the most policy-relevant research questions and working with local policymakers to ensure the answers are heard.

\section{Rapid Research Response to Covid-19}

BRAC Institute of Governance and Development (BIGD)

https://bigd.bracu.ac.bd/all-projects/rapid-research-response-to-covid19/covid-19/

A rapid research response with a special focus on the lives and livelihoods of the poor and vulnerable people. BIGD researchers are using a contacts database conducting phone surveys as well as running research projects in the field. BIGD are collaborating with an extensive network of policymakers, practitioners and researchers to maximise impact of findings.

The objective is to generate actionable understanding of socioeconomic shocks of Covid-19 on vulnerable populations to promote inclusive economic recovery.

\section{CPSE Rapid Response Service}

African Population and Health Research Center (APHRC)

https://aphrc.org/cpse-rapid-response/

APHRC are running a research-to-policy programme called Challenging the Politics of Social Exclusion (CPSE) which includes a rapid response service for partners. Partners are Adam Smith International, Age International, Amsterdam Institute for Global Health and Development, the African Union Commissions, Heinrich-Böll-Stiftung Nairobi, International Association of Gerontology and Geriatrics, Independent University, Ipas, Kenyatta University, Kenya Private Sector Alliance, Netherlands Interdisciplinary Demographic Institute, North-West University, Sida, Sustainable Sanitation Alliance, University of Southampton, and the World Health Organization.

Requests are made through an online response form.

The rapid response was not designed to respond to the pandemic.

\section{Covid Collective}

Institute of Development Studies (IDS)

https://www.covid-collective.net/

A social science research platform to address Covid-19 development challenges hosted by the Institute of Development Studies and funded by the UK Foreign, Commonwealth, and Development Office (FCDO). Southern partners include ACTogether Uganda, African Medical and Research Foundation, African Medical and Research Foundation, Asian Coalition for Housing Rights, BRAC, Cambodia Development Research Institute, CBGA India, University of Malawi, Dialogue on Shelter Trust, Lao PDR University of Health Sciences, IMPACT Trust Kenya, Indian Institute of Public Health, University of Zimbabwe, University of Zambia, Lahore University, Mathare Social Justice Centre, Public Health Foundation India, Science, Technology and Innovation Policy Research Organisation Tanzania, Terres des Hommes Myanmar, University of Ghana, Vietnamese National University of Agriculture, and Yemen Polling Centre.

Grants are commissioned through the platform to support partners to build on existing Covid-19 research and evidence responses, and funds new research responding to emerging need.

The platform supports a range of activities to support mutual learning across sectors globally. 
A hub of think tanks producing research on all aspects of Covid-19 from countries in Africa, Asia, and Latin America complied into an interactive space. Funded by IDRC. Research articles are presented grouped by SDG, region, and most recent. Contributor organisations include Sustainable Policy Institute, Pakistan; Centre for Policy Analysis, Sri Lanka; Institute of Policy Studies, Sri Lanka; The Group for the Analysis of Development, Peru; the Center for the Implementation of Public Policies Promoting Equity and Growth, Argentina; Instituto de Estudios Peruanos (IEP), Peru; and The Institute of Economic Affairs, Kenya.

\section{Evidence Synthesis Response to Covid-19 Crisis}

3ie, Africa Centre for Evidence (ACE), and Global Evidence Synthesis Initiative (GESI) https://www.3ieimpact.org/about-us/Evidence-synthesis-response-Covid-19-crisis

Partnering with the Africa Centre for Evidence, this partnership aims to produce rigorous and timely synthesis to inform non-clinical Covid-19 responses in low- and middle-income countries. Policy briefs include information synthesis on safety net programmes for protecting people from the socio-economic effects of Covid-19.

South African Initiative for Systematic Reviews and Rapid Evidence Syntheses on Health Policies and Systems (SAI) South African Medical Research Council (SAMRC)

https://www.samrc.ac.za/intramural-research-units/HealthSystems-SAI

This rapid review service includes Covid-19 research which is health-related. It is funded by the Alliance for Health Policy and Systems Research. The service aims to develop institutional capacity in low- and middle-income countries for producing systematic reviews. It aims to disseminate the reviews to potential users, particularly decision makers.

\section{The Global South AI4COVID Program https://covidsouth.ai/about}

This programme supports multidisciplinary research focused on evidence-based artificial intelligence (Al) and data science approaches to aid Covid-19 response and recovery in low- and middle-income countries.

It is funded by Canada's International Development Research Centre (IDRC) and the Swedish International Development Cooperation Agency (Sida), with support from Pulse Lab Jakarta of the United Nations Global Pulse network, Gender at Work and Ladysmith.

The eight grantees work in 18 countries in the Global South. Southern organisations include the University of Rwanda, Université Cheikh Anta DIOP (UCAD), Makerere University, University of Peradeniya, Universidad de los Andes, and Tecnología e Innovación (CIECTI) (Argentina).

The programme aims to support research that is linked to government responses and policy making in forecasting Covid-19 transmissions, public health system response, gender inclusion of Covid-19 action, combatting mis-information, strengthening data systems, and digital governance.

\section{Periscope}

Firoz Lalji Institute for Africa, London School of Economics (LSE) https://www.Ise.ac.uk/africa/research/Periscope

Persiscope is hosted by the LSE Firoz Lalji Institute for Africa (FLIA) and is funded by Horizon 2020, the European Union Framework Programme for Research and Innovation. The research project is focused on the social, economic, and behavioural aspects of the Covid-19 pandemic. The consortium involves 32 European institutions.

One of the objectives is to develop a comprehensive atlas to disseminate information for the general public. It also aims to perform statistical analysis on collected data, to identify successful practices and approaches adopted at the local level; and develop guidelines to enhance Europe's preparedness in the future.

The FLIA are also partnering with researchers across Africa to produce information for policymakers worldwide.'

${ }^{1}$ https://www.Ise.ac.uk/africa/research/Covid-19-FLCA accessed 29.10.21 
Covid-19 Learning, Evidence and Research Programme (CLEAR)

Institute of Development Studies (IDS)

https://www.ids.ac.uk/projects/covid-19-learning-evidence-and-research-programme-for-bangladesh-clear/

The CLEAR project is at the beginning of 2.5 years of funding from FCDO, aiming to build a consortium of organisations to produce policy-relevant research and evidence for Bangladesh. It also aims to support uptake among policy-makers and share lessons from the Covid-19 response to help prepare for future shocks. The three themes of focus will be social protection, the secondary impact of health measures, and education.

Scottish Research Council Global Challenges Research Fund (Rapid Response \& Covid-19) FY 2020-21 University of St. Andrews funded by the Scottish Research Council https://impact.wp.st-andrews.ac.uk/sfc-global-challenges-research-fund-rapid-response-covid-19fy-2020-21/

The University of St Andrews put out a call for economic development research projects following Covid-19 in lowincome countries. The aim was to develop partnerships with Southern researchers.

Projects include: evaluating the risk to healthcare workers in Malawi; tracking Covid-19 in Uganda; hospital based Covid-19 response capacity development in Tanzania; and building community-led capacity to respond to Covid-19 in Colombia. ${ }^{2}$

Further details of the process for these projects were not identified within the scope of this review.

\section{PEP Rapid Response Initiative}

Partnership for Economic Policy (PEP)

https://www.pep-net.org/pep-rapid-response-covid-19-pandemic

PEP are supporting seven projects to inform inclusive adaption and recovery from Covid-19, and a further 11 research projects including CORE. The seven projects are exploring Covid-19 and the effects of socioeconomic variables on infections in Brazil; food security in Ethiopia; food security in Nigeria; poverty and government response in Macedonia; macroeconomic impacts through a gender lens in Senegal; and health inequality in South Africa.

Maintains programme: Research supporting social services' adaptation to external shocks Oxford Policy Management https://www.opml.co.uk/projects/researching-how-social-services-can-better-adapt-to-external-shocks

An FCDO-funded research programme in six countries which explored how to improve the resilience of social services during and after external shocks.

Covid-19-related outputs include a disaster risk financing literature review, a report on crisis modifiers for funding health shock response activities, and a review of the impacts of Covid-19 on women.

Food and Nutrition Security Response to Covid-19

International Development Research Centre (IDRC)

https://www.idrc.ca/en/news/documenting-covid-19s-impact-food-systems-sub-saharan-africa

IDRC is funding a number of research initiatives in response to Covid-19 impacts on nutrition and food security. The funding aims to collect short term data on the pandemic and food systems, document responses, and inform recovery policies.

\section{Covid-19 Initiative on the Health of Refugees and Vulnerable Populations}

International Development Research Centre (IDRC)

https://www.idrc.ca/en/news/reducing-impact-covid-19-among-refugee-and-displaced-populations

Aims to provide rapid access to evidence and guidance for countries with refugees and displaced populations on strengthening health system response, documenting evidence on early response, digital health solutions, and sexual and reproductive health and rights. There are a number of projects run under the initiative with an emphasis on evidence-based and locally relevant pandemic responses. 


\title{
3. Knowledge exchange initiatives
}

\author{
South-South Galaxy \\ https://www.southsouth-galaxy.org/response-to-coronavirus/
}

South-South Galaxy are facilitating South-South knowledge exchange with a Covid-19 response mapping. It consists of a dynamic repository of efforts in addressing the outbreak providing fast access to information to compare practices.

South-South Galaxy are a knowledge sharing and partnership brokering platform supported by the United Nations Office for South-South Cooperations (UNOSSC); a number of UN agencies; and development partners including World Health Organization, International Fund for Agricultural Development, The Global Financing Facility Small Grants Programme, and the Finance Charter for South-South Cooperation. ${ }^{3}$ The overall aim is to support developing countries to connect, learn and collaborate with potential partners.

It uses artificial intelligence systems to link existing South-South cooperation platforms.

\section{Astana Civil Service Hub (ACSH) \\ https://www.astanacivilservicehub.org/page/covid-19}

ACSH host a Virtual Alliance of practitioners for exchange of experience in the context of the Covid-19 pandemic. It is a virtual platform to exchange knowledge and best practices in applying innovations and best fit solutions to respond to Covid-19. It includes practical cases, innovative solutions, technologies, and recommendations shared by participating countries and partners. Knowledge and experience gathered aims to support governments in addressing pandemic related challenges and consequences.

Topics include e-Government development, civil service reforms, public administration, and economic reforms.

\section{AfricArXiv \\ https://www.scienceopen.com/collection/f73d064d-e7db-4fa4-bd4a-216af970036c}

AfricArXiv is a digital archive for research communication. "AfricArxiv is dedicated to foster research and collaboration among African scientists, enhance the visibility of African research output and to increase collaboration globally."

\section{Organisation response}

\section{Covid-19 \& Children. Rapid Research Response \\ UNICEF Office of Research - Innocenti \\ https://www.unicef-irc.org/covid19/}

The aims and objectives of this initiative are described on the website: "A rapid research response to provide the evidence needed to scale up rapid assessment, develop urgent mitigating strategies, and prepare interventions to respond to the Covid-19 crisis."

The website highlights UNICEF research publications. A research library is available. There is a collection of evidence syntheses, as well as a collection of blogs and think-pieces. There is also a list of online events.

Southern partnership is not explicit.

\section{Funding network}

\section{GLOPID-R}

https://www.glopid-r.org/

An international network of funding organisations researching for infectious disease preparedness. Objectives include data sharing, determining common priorities, innovative response, and engaging with stakeholders for uptake.

\footnotetext{
${ }^{3}$ https://www.southsouth-galaxy.org/wp-content/uploads/2019/10/South-South-Galaxy-Brochure-1-6-Web-Version.pdf
} 


\section{Suggested citation}

Bolton, L. (2O21) Research initiatives with Southern partners on the impacts of Covid-19. CORE Rapid Review report. Brighton: Institute of Development Studies, DOI: 10.19088/CORE.2021.006

\section{About this report}

This rapid review was produced as part of the Covid-19 Responses for Equity (CORE) Knowledge Translation Programme, which supports the translation of knowledge emerging from the CORE initiative. Supported by the International Development Research Centre, CORE brings together 21 projects to understand the socioeconomic impacts of the pandemic, improve existing responses, and generate better policy options for recovery.

The views expressed herein are those of the authors and do not necessarily represent those of IDRC or its Board of Governors, or IDS.

It is distributed under the terms of the Creative Commons Attribution 4.0 International licence (CC BY), which permits unrestricted use, distribution in any medium, provided the original authors and sources are credits and any modifications or adaptations are indicated.

(C) Institute of Development Studies 2021

DOI: $10.19088 /$ CORE.2021.006 